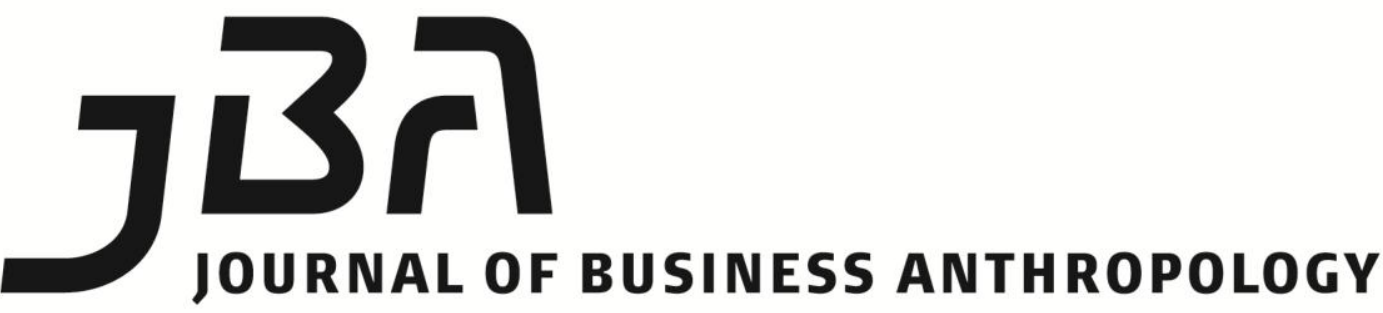

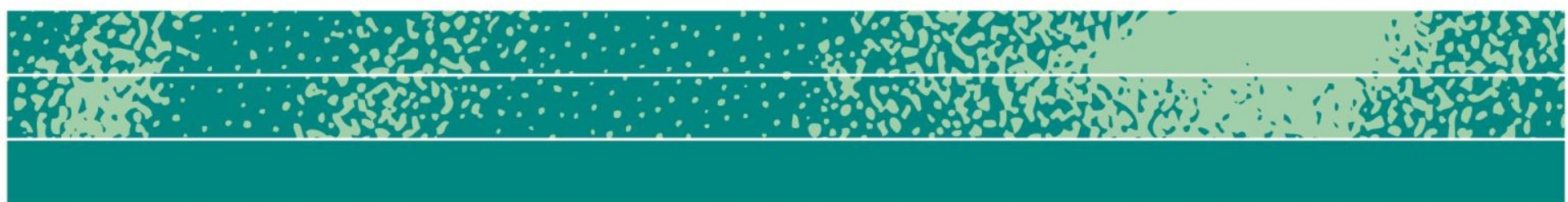

\section{Setting Sail on Stormy Waters: On the Role of Organizational Ethnographers in the Age of Financialization}

\author{
Galit Ailon
}

\begin{abstract}
Current financialization marks a broad cultural shift in the economy. It also marks a cultural shift within organizations. Primarily, it seems to challenge the status of profit as an ultimate measure that no logic transcends, sanctifying in its place the concept of 'shareholder value'. This article discusses this transformation and argues that it has two major implications for organizational ethnographers. First, it holds the potential for overcoming the traditional suspicion towards ethnography in the fields of business and management, and the accompanying wariness towards the type of social reflexivity that ethnography entails. Second, it raises new questions to be asked of the ethnographic method and how new cultural issues might be examined.
\end{abstract}

\section{Keywords}

Financialization, organizational ethnography, organizational culture, profit, shareholder value 


\section{A somewhat cynical take on the traditional ethnographic disadvantage in the fields of business and management}

Imagine a person who seeks to document his life by collecting receipts of everything he has ever purchased. ${ }^{1}$ This person has piles and piles of boxes filled with receipts. He has receipts of every bus and taxi ride he has ever taken; every coffee, cake, and fruit he has ever tasted; every restaurant, bar, and movie theatre he has visited. When he wants to remember what he did in a particular year of his life, where he was, what he wore, ate or drank, he pulls out the box for that year and sifts through its receipts. When he becomes very, very old, he plans to hire an accountant to calculate all his receipts and determine how much his life cost him.

The point of this story isn't the collection itself. Every collection has its charm of aggregation and ordering. The point is the collector's underlying assumption that such a meticulous aggregation of receipts constitutes a documentation of life and value. In this sense, the private collection represents a much wider cultural impulse (see Strathern, 2000) that seems characteristic of a significant portion of the organizational world writ large. To a great extent, the organizational world is a world that insists on thinking of itself in terms of aggregated receipts (given or taken); in terms of an endless flow of price tags that add up to or deduct from each other and finally converge to become an end point, a final number: the bottom line, be it profit or loss.

Organizational ethnographies offer a different perspective, but their perspective is the exception rather than the rule. Human history within organizations has to a great extent been written in terms quite similar to the aggregated receipts I've talked about. In the fields of business and management, any attempt to add a social perspective to these receipts is strikingly restricted. '[A] considerable part of what passes for business or management studies,' says Moeran (2005: 12), 'is based on structured interviews that do not usually allow for more than a scratching on the surface of corporate organization... This is a pity because corporations are a kind of sociological laboratory with histories, cultures, structures, hierarchies and values to observe and analyse.'

Indeed, if we consider the weight of the profit-geared accounting logic in organizations - and I mean 'accounting' in the broad sense of enumerating, measuring, and counting - the very existence of organizational ethnographies would seem surprising. The slow, holistic, and open research, the focus exactly on those things that cannot be counted, the preoccupation with the routine and the everyday - all these are quite removed from the dominant logic in organizational worlds that

\footnotetext{
${ }^{1}$ I would like to thank $J B A$ 's anonymous reviews and the editors, Brian Moeran and Christina Garsten, for their excellent comments and helpful suggestions. I would also like to thank Daniella Arieli and Gideon Kunda for their insightful readings of an earlier version of this paper.
} 
have for decades been run in the shadow of managerial measurement regimes and schemes for maximizing profit. To a great extent, organizational ethnography is a research strategy that manifests and seeks to unravel that which its objects of study apparently seek to forget. Ethnographers who have experienced what the literature often titles 'the problem of access' - in other words, those who have had to face the typical gatekeeping questions, 'how is this study practical?', or 'but why is it important?', or 'what's in it for us?' - know, I assume, what I mean about the power of profit as an ultimate measure that no logic can transcend.

And yet, for decades, organizational ethnographers have been documenting and analyzing the everyday work-lives unfolding in the shadow of managerial profit-making schemes (see Ybema et al, 2009: 34). A great tradition of these anthropologically informed ethnographies (see Moeran and Garsten, 2012) have produced in-depth accounts of the cultural underpinnings and social implications of the managerial models and measurement regimes. They show how organizations are replete with political, cultural, and social forces which, on the one hand, transcend all the managerial schemes, and, on the other, express the hegemonic weight of these schemes. Moreover, many of the findings expose the personal and social prices that the profit ideal carries for those who work in organizations, or who are in other ways related to them. If there is one common theme uniting a diverse set of organizational ethnographies such as those of Robert Jackall (1988), Arlie R. Hochschild (1983), Michael Burawoy (1979), Gideon Kunda (2006), Christina Garsten (2008), and many, many more, it is this: the sanctification of profit as an ultimate measure - as the final and absolute figure that all organizational processes converge onto and must serve - has implications. Profit carries various price tags, many of which are not quantifiable: it demands coping; it lays shadows upon experiences of self and other; it shapes interpersonal dynamics and weighs down on patterns of communication and solidarity.

But the general impression is that among managerial and business scientists, and also among many of those who belong to organizations, all this has not really challenged the validity of the eternal questions ethnographers often face about 'practicality.' In a context that marginalizes the significance of the prices of profit and which excludes the textures of employees' everyday life from its core concept of value, the significance of ethnography becomes dependent on researchers' ability to define its contributions in measureable terms, as a contribution to profit.

This strategy indeed seems increasingly prevalent today. Broadly speaking, organizational ethnography has been linked to profit in two primary ways, both of which have apparently enabled its increasing (but still partial) proliferation. First, there is an acknowledgement of ethnographers' potential marketing-related contributions to furthering the understanding of consumer behavior (see, e.g., Malefyt and Moeran, 
2003). Second, there is an acknowledgement of their potential management-related contributions to efficiency.

While the marketing-based interest seems relatively recent, the managerial interest dates back to the Hawthorne studies of the 1920s and 1930s (Ybema et al, 2009: 3; see also Baba, 2012; Batteau and Psenka, 2012). Nevertheless, the conceptual basis of management's interest in culture has apparently been secured only after Edgar H. Schein's (1985) published his widely cited book on organizational culture and leadership. This interest was, again, predominantly profit-centered. Ever since publication of this book, in most business circles when one speaks of 'organizational culture' one refers to the more-or-less collective thinking modes that sometimes help and sometimes interfere with profit-making. As Westney and Van Maanen (2011: 604) argue, for many practitioners and business scholars 'culture' is that 'soft' and slippery, but nonetheless manageable variable 'that can be dialed up or toned down in order to allow people to work more effectively, to design and sell more and better products or services, or, to be crisp, to add more to the proverbial bottom line.'

In the context of both the marketing-oriented and the managerial interests, there has been, to use Downey and Fisher's (2006: 19; 18) words, a 'corporate hijacking of anthropology,' and a 'phenomenal growth in business anthropology.' Relying upon a long tradition of 'applied' or 'practical' anthropology (see e.g., Goldschmidt, 2001; Baba, 2012; Batteau and Psenka, 2012: 79-80), and on anthropology's historical role in documenting the native's point of the view for those interested in shaping it and controlling its holders, many organizational ethnographers have adopted profit as their application goal. Whether hired by corporations or working within the academy, many contemporary ethnographers conduct research both in organizations and for organizations, or - perhaps more precisely - for the profit-geared productive processes of the settings and subjects of their studies (Cefkin, 2009: 27, 17-18).

As far as the academy is concerned, for organizational ethnographers working in business schools or seeking to publish in academic outlets designated for the business and management fields, the need to package ethnographies as goods that practitioners can clearly discern what they 'can get out of it' in terms of profit measures seems at times an almost unavoidable requirement. The business and management fields have pushed all profit-transcending discussions to the margins of their disciplinary interest. Add to this the relatively new preoccupation with assessment measures within all academic fields, including anthropology (Strathern, 2000), and the result is an accounting bind doubly constraining.

Ethnographically, profit's weight is problematic to the extent that it limits access and focus. The status of profit as the final end point that knowledge should be developed to serve, or against which all life and 
certainly organizational life should be measured, carries the danger of marginalizing the importance of whatever might exist beyond profit: its implications and the personal and social prices it carries within organizations. Millions spend most of their waking hours in organizations, but within many of these organizational settings the textures of their daily experiences are hardly 'counted' in accountings of value. In terms of this article's opening story, a focus on the price tags that are counted means rushing through the corridors of everyday organizational life without losing sight of the ultimate goal, the element that seems most important of all: the piles of receipt-filled boxes. This is what being practical is often taken to mean.

\section{Why there is reason to believe that change is coming}

Something is changing from an unexpected direction: financialization. 'Present-day capitalism,' write Pryke and du Gay (2007: 339), 'is increasingly financial in its character. At almost every turn... private finance, its markets and their effects are working their way into most areas of everyday life.' Indeed, the facts that there is a broad 'shift in the economy towards a finance-centered system' (Davis, 2010: 75; Davis, 2009; Langley, 2004), and that financialization has become a prime trajectory in that accumulation increasingly occurs through financial channels (Krippner, 2005), have entailed a pervasive financial 'shift in worldviews' and 'sensibilities' (Davis, 2010: 79).

This shift in worldviews and sensibilities entails a challenge to the ontological status of profit as an ultimate measure and end-point in organizations. This challenge is twofold. First, financialization is increasingly subordinating 'profit' to a partially interrelated figure 'shareholder value' - whose cultural and economic status has been strengthening since the 1980s (Ho, 2009; Davis, 2009). Today, financial markets have to a great extent 're-formatted the institutions of the corporate economy and oriented corporations toward shareholder value as their guiding star' (Davis, 2009: 5). Indeed, as Ho (2009: 122-123) explains in an ethnographic study of Wall Street bankers, while "'shareholder value" continues to be a black box,' in the post-millenary era it has also 'become a part of mainstream every-day discourse.' Today, she continues, it is generally taken-for-granted that shareholder value 'should be the main goal for all corporations,' and that 'stock prices... are the focus and the measure of corporate health and success' (pp. 126, 153).

In other words, the survival of corporations is seen today as increasingly dependent upon the price that financial actors in stock markets are willing to pay for a stock. Interestingly, while related to the concept of profit, the price of a stock is also becoming significantly removed from it, so that the financial world increasingly problematizes the link between profit and stock price. Different studies of financial markets repeatedly show that the prices of financial commodities, 
including stocks and their derivatives, are increasingly seen as a barometric measure of and a means for articulating and manipulating the collective expectations and constantly shifting social 'mood' of the market (see in this regard, e.g., Knorr Cetina and Bruegger, 2000; Langley, 2010; Zaloom, 2009: 256-266). Notions of prices as reflecting 'real,' 'absolute,' or 'objective' economic value that is directly based upon profit are increasingly subordinated to perceptions of these prices as representing above all - the social dynamics and interpretive moods of market participants.

Given the fluidity, ambiguity, and heightened pace of financial trading, financial prices are thus 'momentary markers of approximate valuations' based on specifically social information and scenarios that transpire between market participants (Zaloom, 2003: 2). The stock market's underlying rationale of making shareholding liquid - in other words, of making stocks easily convertible into cash or other stocks implies that stock prices represent a particular set of values historically divergent from corporations (Ho, 2009: 184). For example, as Ho (2009: 185) further notes, 'the price of a stock can be stratospherically high or "undervalued," yet correspondingly little has changed in the corporate organization itself.' In this context, the market-based 'social emotions' (Pixley, 2004) that were once deemed 'irrational' (see, e.g., Kindleberger, 1989) in the sense of leading to price distortions - the collective fear, euphoria, mania, panic, and so forth of stock market participants - are increasingly seen as the prime determinants of prices and gain considerable attention within financial markets. Indeed, the marketing efforts of 'investor relations' professionals (see Zuckerman, 1999) are directly geared at affecting them.

As financial prices become dependent upon market mood swings influenced, at least in part, by 'investor relations' efforts and by the social dynamics occurring amongst market participants, they become much more loosely coupled to some clear notion of an objective corporate value as represented by the figure of profit. In a sense, then, financial markets are increasingly characterized by a reflexive awareness of the interpretive space that shapes stock prices in a constantly changing kind of way that is not always or directly linked to profit.

The second way in which financialization undermines the status of profit as an ultimate measure in organizations is related to the recent sensational financial crises, and the accounting debacles of quite a few well-known organizations (see, e.g., Ailon, 2011; Boje et al, 2004; Williams, 2008). These debacles have raised public awareness of accounting's significant degrees of interpretive freedom. Although retrospectively interpreted as unique and deviant events (e.g., Ailon, 2011; 2012; Williams, 2008), these sensational debacles have nonetheless also publicly illustrated the extent to which the bottom line may not be as clear cut and straightforward as it might at first appear. They have 
brought to the surface the fact that - like other types of assessment and measurement outcomes - it, too, rests on considerable creative license and interpretive space (see, e.g., Strathern, 2000).

Thus, this is a time when the survival of an organization increasingly depends on the way in which analysts, speculators, investors, and financial traders interpret the impact of the bottom line - as well as of the future, yet unknown, bottom lines - on the stock price. This is also a time characterized by an increasing awareness of the indeterminism of calculations in financial statements. Indeed, the financial age seems to mark a historical moment in which the economic mathematical obsession has become so extreme that it exposes its own impossibility: the instability and ambiguity of that which has until now been deemed 'exact'; its susceptibility to manipulation; the way that every number is a narrative; the lack of closure of the figures taken to be 'final.' To use Zaloom's (2006: 142) words, 'fluid' financial numbers lack the status of definitive statements. In contrast to the 'firm' numbers that have been foundational for accounting, financial numbers undermine notions of numerical stability and transparency: they turn numbers into objects of interpretation rather than of calculation.

Perhaps paradoxically, then, finance brings the interpretive space surrounding numbers into awareness. It problematizes notions of numbers as self-contained and context-free (see Crump, 1990, esp. p. 147). In a sense, finance thus entails an anthropological sensibility. Indeed, anthropologists of finance have begun to note parallels of form between anthropological knowledge practices and technocratic/financial knowledge practices in banking and accounting (Maurer, 2002; Riles, 2006), going so far as to identify 'para-ethnography' - the reflexive endowment of information with social perspective and meaning - as an inherent part of financial sense making (Holmes and Marcus, 2006).

The increasing financial emphasis on the 'fluid,' interpretive, and malleable foundations of the 'firm' numbers and 'exact' figures seems part of a wide and encompassing cultural change. As Zygmunt Bauman argues, 'liquidity' is the metaphor of our time. Until not long ago, he maintains, the modern era's characteristic search for 'lasting solidity, a solidity which one could trust and rely upon and which would make the world predictable and therefore manageable' (Bauman, 2000: 3), had involved 'shedding the "irrelevant" obligations standing in the way of rational calculation of effects, as Max Weber put it...' (ibid., p. 4). In contrast, 'the present-day situation emerged out of the radical melting of the fetters and manacles rightly or wrongly suspected of limiting the individual freedom to choose and to act' (ibid., p. 5). Thus, Bauman notes, patterns of dependency and interaction are now malleable to an extent not experienced by past generations:

It would be imprudent to deny, or even to play down, the profound change which the advent of 'fluid modernity' has 
brought to the human condition. The remoteness and unreachability of systemic structure, coupled with the unstructured, fluid state of the immediate setting of life-politics, change that condition in a radical way and call for a rethinking of old concepts that used to frame its narratives.

(Bauman, 2000: 8)

Profit seems to be one of those narratively pivotal concepts. In the cultural context of 'liquid modernity,' and more specifically of the financial 'liquidation' of the old corporate 'solids,' profit loses its power and status as an ultimate measure in organizations.

For organizational ethnographers this might actually mean a form of liberation. It might mean a welcome release from the 'solid' regime of calculation which has long hindered their access to organizations and limited their ability to bring to attention anything that transcends the final goal of calculation, namely profit. As the interpretive space that has long sustained the dominance of profit is revealed and brought into awareness, there seems to be a corresponding space exactly for the sort of studies that view the interpretive space surrounding profit as the focus of their inquiry. Now there might actually be a chance for organizational ethnographers to be heard: To raise awareness of the complex layers of meaning sustaining the supposedly 'practical' or 'real' world, and to broaden the meaning of the concept of value so that it could include the prices of profit as well.

I don't want to sound naïve or present the financial turn as Utopian. In Liquidated (2009), an ethnography of Wall Street bankers, Karen Ho shows how the sanctification of 'shareholder value' creates a situation in which the dismantling and realigning of corporations as a means for creating this 'shareholder value' have become routine on Wall Street. They give rise to an unstable and shaky employment world that is increasingly cast in the image of the financial market to which it is subordinated. Indeed, 'employees, located outside the corporation's central purpose, are readily liquidated in the pursuit of stock price appreciation' (Ho, 2009: 3). In this sense, the loosening of the power and status of 'profit' as the ultimate measure, and its replacement with an uncertain, unstable, peripatetic 'shareholder value', is nothing but a replacement of one sanctified number with another, which carries its own social and personal prices.

Nonetheless, while 'shareholder value' represents an economic regime that might currently be no less harsh or problematic than earlier regimes, it is perhaps more easily susceptible to the ethnographic gaze, and more potentially attentive to ethnographic sensibilities and to the type of socially-attuned findings that they bring to light. As anthropologist Maurer and Intel's Mainwaring (2012: 183) illustrate in an account of their collaboration, business organizations' financial focus seems to harbor 'a willingness to experiment with different disciplines and 
methodologies.' Indeed, '[i]n money and finance, our work helped tell a... story, about a system that could make, handle, manage money and finance in a more humane way, or to serve human agendas' (ibid., p. 190).

Indeed, the recent growth of the field of the anthropology of finance further indicates that financialization might involve a more welcoming environment for organizational ethnographers. Quite a few recent ethnographic studies have been conducted within organizations by anthropologists of finance. These include Riles (2011) who studied an investment bank; Holmes (2009) and Abolafia (2010) who studied central banks; and Zaloom (2006) and Miyazaki (2003) who studied futures/securities trading firms. These and other anthropologists of finance have tended to focus on the organizations' financial-market dealings rather than on their inner organizational realities. But the fact that they obtained anthropological access, and the socially attuned findings that they then reported, indicate at least some potential new possibilities for organizational ethnographers, too, in these and other types of organizations. In this sense, the development of the field of the anthropology of finance in the last decade and a half might be said to mark the contours of a new space that is opening up for organizational ethnographers as well.

Thus, my argument is not designed to be Utopian so much as practical - but practical in an ethnographic sense. The subordination of the logic of production to the logic of financial circulation (LiPuma and Lee, 2004) represents a deep cultural change that challenges not only managerial schemes but also the dominance of schematic thinking. It brings to awareness the existence of an interpretive space that for all too long and all too often has been denied or schematized as a problematic or slippery variable, minor in relation to the 'solidity' of numbers. In this sense, subordinating the logic of production to the logic of financial circulation may represent an opportunity for a type of listening that organizational ethnographers usually have not received in business and managerial circles.

\section{New questions to be asked}

Anthropologists LiPuma and Lee (2004), two amongst a growing group of anthropologists studying the development and significance of financial culture, have argued that the changes brought about by and through financialization signify a new stage of global capitalism. Production processes still represent a central and core moment in this new stage of capitalism, but a moment increasingly subordinated to financial circulation processes; to the rising power of speculative capital. One prevalent expression of this is the significant strengthening of finance departments within corporations. As Lipuma and Lee (2004: 91-92) comment with regard to the financial arms of major corporations: 
Originally designed to help customers finance the purchase of the products manufactured by the industrial division and to implement insurance hedging strategies, these financial arms are now growing faster than their manufacturing cousins and also becoming increasingly disconnected from production in that their financial activities, products, and global presence bear a much stronger resemblance to investment banks and to hedge funds than to divisions of conventional manufacturing firms. ... And as global financial circulation, crowned by the derivatives markets, has mushroomed, the growth rates and profitability of these financial divisions have become significantly greater than those of their once predominant manufacturing parents.

Another prevalent organizational expression of financialization is to be found in shareholder-value oriented theories of 'corporate governance,' which portray the increasing structural dominance of financial logic within organizations. In these theories, 'the corporation [is] no longer portrayed as a tangible institution with an inside and an outside, as in the industrial-managerialist days' (Davis, 2009: 21). He continues: 'Rather it [is] a network, a "nexus of contracts," organized in such a way as to promote the creation of shareholder value.'

The loss of the production-centered view and production-centered structure is an inner-organizational expression of the changing connection between profit and corporate survival. In the context of the rising dominance of the shaky and largely unpredictable speculative capital, the deepest foundations of the thought practices and meaning systems within organizations are being transformed.

This process opens up many new questions for organizational ethnographers and entails new challenges. What happens in organizations when 'firm' numbers become 'fluid'? What happens when the interpretive links between effort, profit, economic value, and stock price - all traditional links between means and ends - are problematized and rendered insecure? What happens in a cultural context that opens up these links for reflection; that renders them floating social constructs rather than stable, taken-for-granted, and absolute 'truths'? What happens when the interpretive links between what people actually dotheir actual work hours, effort, sacrifices - and the sanctified end figure become obscure and visibly open to interpretation and reconsideration?

Not only does all this appear to amount to a significant cultural change in organizations themselves, but it also seems to be a change that calls for new sensibilities; for new ways of thinking and new analytical instruments. It is a change which makes it possible to challenge longrooted institutions that are based on the sanctification of measurement and profit, and to realize that the justification for their existence has been destabilized in the context of the current financial flooding of global capitalism. 
For example, anthropologists Jean and John Comaroff have argued that in some places in the world a striking corollary to what they refer to as 'millenial capitalism' has been the proliferation of occult economies. '[F]inance capital has always had its spectral enchantments,' they remark (Comaroff and Comaroff, 2000: 310), 'its modes of speculation based on less than rational connections between means and ends.' Moreover, 'as the connections between means and ends become opaque, more distended, more mysterious, the occult becomes an ever more appropriate, semantically saturated metaphor for our times' (ibid., p. 317). Thus, they argue, ' $[\mathrm{m}]$ agic is, everywhere, the science of the concrete, aimed at making sense of and acting upon the world...' (p. 318). ${ }^{2}$ Attempting to conjure up or account for wealth by appealing to techniques that defy explanation in conventional terms of practical reason and to offer moral discourses and actions sparked by the real or imagined production of value through such 'magical' means (ibid., p. 310), occult economies answer the economic perplexities of our times with images of insidious forces and alluring mysticism; of potent magical technologies and modes of accumulation.

Indeed, magic seems to have much in common with attempts to mathematically 'manage' financial uncertainty. Both represent forms of enchantment with the un-known and the pretense and effort to affect it in a way that will bring about future results which fit the wishes of those who pay or invest. Notions of 'risk management' (see Ailon, 2012), with their characteristic statistical sophistication and financial technical intricacies that only very few seem to grasp (Lipuma and Lee, 2004: 61), appear to stem from the same underlying cultural impulses and preoccupations as those of its supposedly primitive opposites: magic and wizardry. Indeed, like magic and wizardry, they can be put to various uses and misuses, including the extraction of gains and the practice of forms of power and manipulation outside the realm of organizations and beyond their mechanisms of social and regulatory controls. The increasing popularity of financial markets thus represents new types of capitalist enchantments that are also simultaneously quite old. Indeed, it is characterized by an impulse both to tame the unknown and to know it, as well as by a tendency to mystify it.

The big ethnographic question here is: what are the cultural changes occurring within organizations in such a context? What type of organizational cultures develop in the shadow of these new types of capitalist enchantments with the unknown? In the shadow of the passion to manage a capricious and temperamental economic future? In the shadow of statistical spells and magical mathematics, of the sweet temptations and harsh punishments of the financial 'invisible hand'? What happens in organizational worlds whose longings and fears are increasingly entangled with the panics and euphoria of investors and

${ }^{2}$ See also Williams (1980) on advertising as a 'magic system.' 
speculators? What happens when the economic version of Bauman's metaphor of liquidity - liquid money, liquid structures, liquid markets, liquidated companies and workforces - casts a growing shadow over a world which has traditionally thought of itself in terms connoting a clear, ordered, and stable causal logic: a machine, a body, a system, indeed an 'organization'?

As I mentioned earlier, most of the anthropological work done so far focuses on financial market culture, and there is hardly enough ethnographic work that delves into the ways contemporary organizational cultures are influenced by financialization and the strengthening of financial markets. Indeed, while many anthropologists of finance have conducted their ethnographic fieldwork in organizations, their work tends to focus on the market rather than on the organizations themselves. Ho (2009), who conducted ethnographic work among Wall Street bankers, is somewhat of an exception, as her argument explicitly ties the cultures of Wall Street workplaces to market approaches and behavior.

There seems to be a striking need to continue with this line of work and conduct anthropologically-attuned studies of financialization processes within organizations as well. More specifically, there seems to be a need to examine the ways in which financial markets impact and reshape the inner logic of means and ends, effort and return, in diverse types of organizations. There is, further, a need to place the question of value itself at the center of attention (Batteau and Psenka, 2012): to trace the processes of its construction, the negotiations over its meaning, the types of market images it is tied to, and the ways it is linked to visions and concepts of practicality. Moreover, there are other questions to be explored: what are the role, power, and place of financial departments within organizations? How are they linked to other domains of work? Current financial developments, and especially the increasing prevalence of the financial prism, open up many new organizational questions. The recent growth in anthropological studies conducted within financial organizations indicates that now there might be a chance that the barriers of entrance and the barriers of attention that organizational ethnographer have long had to face might also become a little more liquid.

\section{Closing Note}

A confession: throughout this discussion I have tried my best to circumvent the oft-traveled road of the critical/managerial divide with its rocky ideological topography. I assume that I have been only partially successful in this endeavor, and that, from time to time, visions of this road's imposing landscapes - Marxism, neo-Marxism, liberalism, neoliberalism, post-structuralism, and so on and so forth - have popped up in the minds of my readers. I also assume that my own critical loyalties have no doubt been discernible to those who have traveled this road before. 
And yet I insist on the fact that my point is primarily ethnographic. The transformations brought forth by financialization affect the deepest layers of the cultural fabric of organizations. In this discussion, I have focused upon their impact on the significance of the concept of 'profit.' I have argued that financialization has directly and notably challenged the status of profit as an end measure in organizations, subordinating it to the much more fluid 'shareholder value.' I have also argued that financialization 'liquidates' many of the solidities of the recent past, not least of which are the numerical convictions, schematic thinking habits, and accounting assurances that all too often have been used to deny or marginalize the 'soft' and 'slippery' interpretive spaces and daily experiences to which ethnographers devote their careers.

I have also argued that these cultural transformations entail a practical advantage and an anthropological challenge for organizational ethnographers. Practically, there seems to be at least a reasonable chance that the obstacles of access and attention that ethnographers have had to face for decades will be to some extent lifted. Ethnographers seem especially well equipped to wonder beyond profit: to explore the social and personal prices that profit entails, and to take note of those aspects of everyday life that are not 'counted' in accountings of value, even though they are of utmost value for any in-depth attempt to document or understand organizational life in all its intricacy. Anthropologically, financialization implies that there are many new questions to ask. A deep cultural turn is under way and its organizational expressions and implications have barely been studied.

So imagine, again, a person who seeks to document his life by collecting receipts of everything he has ever purchased. One day a financial flood occurs. It overflows his box-filled closet and washes all his receipts out to a stormy sea. Ethnographers who want to know what happens next must set sail on these stormy waters, and observe.

\section{References}

Abolafia, Mitchel Y. 2010. 'Narrative construction as sensemaking: how a central bank thinks.' Organization Studies 31(3): 349-367.

Ailon, Galit. 2011. 'Mapping the cultural grammar of reflexivity: the case of the Enron scandal.' Economy and Society 40 (1): 141-166.

Ailon, Galit. 2012. 'The discursive management of financial risk scandals: the case of Wall Street Journal commentaries on LTCM and Enron.' Qualitative Sociology 35(3): 251-270.

Baba, Marietta L. 2012. 'Anthropology and business: influence and interests.' Journal of Business Anthropology 1(1): 20-71.

Batteau, Allen W. and Carolyn E. Psenka. 2012. 'Horizons of business 
anthropology in a world of flexible accumulation.' Journal of Business Anthropology 1(1): 72-90.

Bauman, Zygmut. 2000. Liquid Modernity. Cambridge: Polity Press.

Boje, David M., Rosile, Grace Ann, Durant, Rita A., and John T. Luhman. 2004. 'Enron spectacles: a critical dramaturgical analysis.' Organization Studies: 25(5): 751-774.

Burawoy, Michael. 1979. Manufacturing Consent: Changes in the Labor Process under Monopoly Capitalism. Chicago: The University of Chicago Press.

Cefkin, Melissa. 2009. 'Introduction: business, anthropology, and the growth of corporate ethnography.' In Cefkin Melissa (ed.), Ethnography and the Corporate Encounter: Reflections on Research in and of Corporations. NY: Berghahn Books, pp. 1-40.

Comaroff, Jean and John L. Comaroff. 2000. 'Millennial capitalism: first thoughts on a Second Coming.' Public Culture 12(2): 291-343.

Crump, Thomas. 1990. The Anthropology of Numbers. Cambridge: Cambridge University Press.

David, Gerald F. 2010. 'Not just a mortgage crisis: how finance maimed society.' Strategic Organization 8(1): 75-82.

Davis, Gerald F. 2009. Managed by the Markets: How Finance Re-Shaped America. Oxford: Oxford University Press.

Downey, Greg and Melissa S. Fisher. 2006. 'Introduction: The Anthropology of Capital and the Frontiers of Ethnography.' In Melissa S. Fisher and Greg Downey (eds.), Frontiers of Capital: Ethnographic Reflections on the New Economy. Durham: Duke University Press, pp.1-30.

Garsten, Christina. 2008. Workplace Vagabonds: Career and Community in Changing Worlds of Works. UK: Palgrave Macmillan.

Goldschmidt, Walter. 2001. 'Notes toward a theory of applied anthropology.' Human Organization 60(4): 423-429.

Ho, Karen. 2009. Liquidated: An Ethnography of Wall Street. Durham: Duke University Press.

Hochschild, Arlie R. 1983. The Managed Heart: Commercialization of Human Feeling. Berkeley: University of California Press.

Holmes, Douglas R. 2009. 'Economy of words.' Cultural Anthropology 24(3): 381-419.

Holmes, Douglas R. and George E. Marcus. 2006. 'Fast capitalism: paraethnography and the rise of the symbolic analyst.' In Melissa S. Fisher and Greg Downey (eds.), Frontiers of Capital: Ethnographic Reflections on the New Economy. Durham: Duke University Press, pp. 33-57.

Jackall, Robert. 1988. Moral Mazes: The World of Corporate Managers. 
Oxford: Oxford University Press.

Kindleberger, Charles P. 1989. Manias, Panics, and Crashes: A History of Financial Crises. Revised Edition. NY: Basic Books.

Knorr Cetina, Karin and Urs Bruegger. 2000. 'The market as an object of attachment: exploring postsocial relations in financial markets.' Canadian Journal of Sociology 25(2): 141-???.

Krippner, Greta R.. 2005. 'The financialization of the American economy.' Socio-Economic Review 3: 173-208.

Kunda, Gideon. 2006. Engineering Culture: Control and Commitment in a High-Tech Corporation (revised edition). Philadelphia: Temple University Press.

Langley, Paul. 2004. 'In the eye of the "perfect storm": the final salary pensions crisis and the financialisation of Anglo American capitalism.' New Political Economy 9(4): 539-558.

Langley, Paul. 2010. 'The performance of liquidity in the subprime mortgage crisis.' New Political Economy 15(1): 71-89.

LiPuma, Edward and Benjamin Lee. 2004. Financial Derivatives and the Globalization of Risk. Durham: Duke University Press.

Malefyt, Timothy de Waal and Brian Moeran. 2003. 'Introduction: advertising cultures - advertising, ethnography and anthropology.' In T. De W. Malefyt and B. Moeran (eds.), Advertising Cultures. Oxford: Berg. Maurer, Bill. 2002. 'Anthropological and accounting knowledge in Islamic banking and finance: rethinking critical accounts.' Journal of the Royal Anthropological Institute 8: 645-667.

Maurer, Bill and Scott D. Mainwaring. 2012. 'Anthropology with business: plural programs and future financial worlds.' Journal of Business Anthropology 1(2): 177-196.

Miyazaki, Hirokazu. 2003. 'The temporalities of the market.' American Anthropologist 105(2): 255-265.

Moeran, Brian. 2005. The Business of Ethnography. Oxford: Berg. Moeran, Brian and Christina Garsten. 2012. 'What's in a name? Editors' Introduction to the Journal of Business Anthropology.' The Journal of Business Anthropology 1 (1): 1-19.

Pixley, Jocelyn. 2004. Emotions in Finance: Distrust and Uncertainty in Global Markets. Cambridge: Cambridge University Press.

Pryke, Michael and Paul du Gay. 2007. 'Take an issue: cultural economy and finance.' Economy and Society 36 (3): 339-354.

Riles, Annelise. 2006. 'Real time: unwinding technocratic and anthropological knowledge.' In Melissa S. Fisher and Greg Downey (eds.), Frontiers of Capital: Ethnographic Reflections on the New Economy. 
Durham: Duke University Press, pp. 86-107.

Riles, Annelise. 2011. Collateral Knowledge: Legal Reasoning in the Global Financial Markets. Chicago: University of Chicago Press.

Schein, Edgar H. 1985. Organizational Culture and Leadership. San Francisco: Jossey-Bass.

Strathern, Marilyn (ed.) 2000. Audit Cultures: Anthropological Studies in Accountability, Ethics and the Academy. London: Routledge.

Westney, Eleanor D. and John Van Maanen. 2011. 'The casual ethnography of the executive suite.' Journal of International Business Studies 42: 602607.

Williams, James W. 2008. 'The lessons of "Enron": media accounts, corporate crimes, and financial markets.' Theoretical Criminology 12 (4): 471-499.

Williams, Raymond. 1980. Problems in Materialism and Culture. London: Verso.

Ybema, Sierk, Dvora Yanow, Harry Wels, and Frans Kamsteeg. 2009. 'Studying everyday organizational life.' In Sierk Ybema, Dvora Yanow, Harry Wels, and Frans Kamsteeg (eds.), Organizational Ethnography: Studying the Complexities of Everyday Life. LA: Sage, pp. 1-20.

Zaloom, Caitlin. 2003. 'Ambiguous numbers: trading technologies and interpretation in financial markets.' American Ethnologist 30 (2): 1-15.

Zaloom, Caitlin. 2006. Out of the Pits: Traders and Technology from Chicago to London. Chicago: The University of Chicago Press.

Zaloom, Caitlin. 2009. 'How to read the future: the yield curve, affect, and financial prediction.' Public Culture 21 (2): 245-268.

Zuckerman, Ezra. 1999. 'The categorical imperative: securities analysts and the illegitimacy discount.' American Journal of Sociology 104 (5): 1398-1438.

Galit Ailon is a Senior Lecturer in the Department of Sociology \& Anthropology at Bar-Ilan University, Israel. She has conducted fieldwork on an Israeli-American high-tech merger (published as Global Ambitions and Local Identities, Berghahn, 2007), as well as in other organizational and market sites. She has published in such journals as The Academy of Management Review, Organization Studies, and Economy and Society, and may be reached at Galit.ailon@biu.ac.il 